\title{
POR LOS CAMINOS DE LA MEMORIA EN LA OBRA DE MARCEL PROUST
}

Edgar Vite*

RESUMEN: en este ensayo se analiza el papel de la reminiscencia en la obra de Marcel Proust, especialmente en En busca del tiempo perdido y su relación con la construcción de la identidad de los protagonistas de sus novelas. La memoria permite acceder al pasado individual y los recuerdos se vuelven una forma peculiar de autoconocimiento. Proust muestra cómo es posible reconstruir la historia personal por medio de la memoria y de la búsqueda del tiempo perdido.

$$
\text { rode }
$$

ABSTRACT: In this article, we analyze the role of reminiscence in Marcel Proust's work, especially In Search of Time Lost and its relationship with the construction of his protagonists' identities. Memory provides access to the personal past and thus becomes a unique form of self-awareness. Proust demonstrates how it is possible to access one's personal history through memories and the search of time lost.

PALABRAS ClAVE: Proust, reminiscencia, memoria, identidad, tiempo perdido. KEY WORDS: Proust, reminiscence, memory, identity, time lost.

RECEPCIÓN: 6 de junio de 2011.

APROBACIÓN: 23 de agosto de 2011.

* Departamento Académico de Estudios Generales, ITAM. 
La reproducción total o parcial de este artículo se podrá hacer si el ITAM otorga la autorización previamente por escrito. 


\title{
POR LOS CAMINOS DE LA MEMORIA EN LA OBRA DE MARCEL PROUST
}

\author{
La memoria es el espacio en que se atesoran los \\ recuerdos, las fantasías retrospectivas y los olvidos \\ que se atribuyen al yo. No soy porque actúo, \\ ni porque pienso. Recuerdo, luego existo. \\ Soy quien recuerda haber sido. ${ }^{1}$
}

\section{Proust no entiende el regreso al} pasado únicamente como un mecanismo gnoseológico, como un proceso psicológico o como un experimento científico, sino más bien como una búsqueda personal, cuya meta principal consistirá en recobrar lo aparentemente irrecuperable. De este modo, pretendo demostrar cuáles son las características e implicaciones que conforman dicha búsqueda. En este mismo sentido, es necesario aclarar que, a pesar de que el carácter autobiográfico es fundamental para comprender el significado de esta novela, la voz del narrador no debe confundirse con la del autor.

En un primer acercamiento, la memoria se revela como la retención de una serie de imágenes mentales, que aparentemente carecen de lógica y claridad. En esta medida, los recuerdos pueden presentarse con mayor o menor intensidad, de acuerdo a las circunstancias. ${ }^{2}$ Marcel Proust compara la memoria con un cinescopio, que proyecta una serie de filminas borrosas y discontinuas. El narrador de esta novela considera que posee una memoria privilegiada, lo que le ha permitido retener sus recuerdos con mayor nitidez y durante un período más largo de tiempo:

Estas evocaciones arremolinadas y confusas nunca duraban más que algunos segundos; a menudo, mi breve incertidumbre del lugar en que me p. 19.

'Blas Matamoros, “Introducción”, Por el camino de Proust, 1988, Barcelona, Anthropos,

${ }^{2}$ Vid. Thomas Reid, La filosofía del sentido común, 1998, México, UAM, trad. José Hernández, p. 201. 
EDGAR VITE

hallaba no distinguía mejor unas de otras las diversas suposiciones de que estaba hecha, que lo que podemos aislar, al ver correr un caballo en el cinescopio, las posiciones sucesivas que se nos muestran. Pero yo había vuelto a ver una u otra de las piezas que había habitado en mi vida y terminaba por recordarlas a todas en las largas ensoñaciones que seguían a mi despertar. ${ }^{3}$

Uno de los rasgos de esta facultad que más ha sido estudiado consiste en que permite conservar las experiencias pasadas, a pesar de que éstas dejaron de ser. La memoria juega un papel central en el conocimiento, pues sin ella el proceso cognitivo no sería acumulativo ni progresivo. Por otro lado, la memoria permite reconocer el cambio y la identidad de las cosas, que es indispensable para desenvolverse en el mundo. Sobre este punto, el filósofo escocés Thomas Reid afirma que: "Es por la memoria que adquirimos un conocimiento inmediato de las entidades pasadas. Los sentidos sólo nos dan información sobre las cosas mientras ellas existan en el momento presente, pero si esa información no es preservada en la memoria, desaparecerá instantáneamente y nos dejará tan ignorantes como si las cosas presentes jamás hubiesen existido". 4

El sueño es uno de los mecanismos que activa la memoria, pues además de revelarnos lo que es reprimido por el inconsciente, abre una puerta hacia el interior del sujeto, produciendo una percepción muy particular del tiempo. En esta medida, el sueño adquiere un lugar central en la relación del individuo con su pasado y sobre todo en el caso de su infancia. Los recuerdos preservados por la memoria devuelven una serie de experiencias que parecían haberse perdido para siempre, pero que de pronto es posible recuperar de forma vívida.

La vuelta o regresión del sujeto a sus primeros años de vida es lo que Proust ha denominado la búsqueda del tiempo perdido. En primera instancia, dicha búsqueda producirá cierta melancolía, que se tornará en frustración cuando el sujeto se dé cuenta de que resulta

${ }^{3}$ Marcel Proust, En busca del tiempo perdido, 2000, Argentina, Losada, trad. Estela Canto, p. 15. A partir de ahora citaré sólo las páginas de esta edición.

${ }^{4}$ Thomas Reid, op. cit., p. 201. 
imposible recobrar el pasado tal como ocurrió. Al respecto, el narrador cuenta el momento en que regresa a casa de sus padres y entra a su cuarto de la infancia, pero es incapaz de reconocerlo, al menos no como lo recuerda: "Pero mi tristeza aumentaba en consecuencia, pues nada más que el cambio de iluminación destruía la costumbre que yo tenía de mi cuarto, y gracias a ella -sin contar el suplicio de acostarme- se me había vuelto soportable. Ahora ya no lo reconocía y estaba inquieto en él, como en un cuarto de hotel o de "chalet" adonde hubiera llegado por primera vez al bajar del tren.” (p. 18)

Esta característica de la obra de Proust ha sido denominada por algunos críticos, entre los que se destaca a Gilles Deleuze, como una búsqueda por alcanzar la verdad. En este sentido, es posible plantear que el escritor francés no se interesa por la apariencia de las cosas, sino por su esencia. Sin embargo, desde mi perspectiva, más que tratarse de una relación cognoscitiva con el mundo, establece una conexión vital con él, pues no pretende alcanzar una verdad objetiva, sino descubrir el modo en que la subjetividad permea todo lo que nos rodea. Por esta razón, no se trata de una búsqueda exterior de la verdad, sino más bien de descubrir el modo en que el sujeto se refleja en el mundo. ${ }^{5}$

La conexión entre el sueño y la memoria da lugar a algunas dificultades gnoseológicas que es necesario puntualizar, destacando el papel de la imaginación en el proceso de reminiscencia. La diversidad de ensoñaciones que se experimenta cotidianamente genera ambigüedad e incertidumbre en el sujeto que las experimenta, pues no siempre puede distinguir la percepción sensible de la imaginación. Por esta razón, durante el sueño es posible confundir lo real con lo ficticio:

También, al dormir, había alcanzado sin esfuerzo una edad para siempre transcurrida de mi vida primitiva, había vuelto a encontrar alguno de mis terrores infantiles, como el de que mi tío abuelo me tirara de los bucles y que se había disipado el día -fecha para mí de una nueva eraen que me los había cortado. En el sueño había olvidado este acontecimiento y sólo volvía a recordarlo cuando lograba despertar para escapar de las manos de mi tío abuelo; después, como medida de precaución, me envol-

${ }^{5}$ Vid. Gilles Deleuze, Proust y los signos, 1964, Barcelona, Anagrama, p. 24. 
vía completamente la cabeza con la almohada antes de retornar al mundo de los sueños. (p. 12)

La literatura produce este tipo de experiencia ambivalente. Esto revela la fuerte inclinación de Marcel Proust hacia todo aquello que implica una forma de ilusión, en donde la realidad se mezcla con la ficción. La literatura implica una vivencia de otro orden, pues mientras leemos se produce un proceso de interiorización que nos transporta a otros mundos. La literatura revela la diferencia temporal entre la ficción y la vida, pues es capaz de sintetizar largos años de experiencia o de alargar a tal grado un instante que incluso parezca interminable:

Y una vez que el novelista nos ha puesto en este estado, en el cual, como en todos los estados puramente interiores, toda emoción se duplica, en el cual su libro va a turbarnos como nos turba un sueño, pero un sueño más claro que los que tenemos cuando dormimos y cuyo recuerdo se prolongará más, entonces, él desencadenará en nosotros, durante una hora, todas las dichas y todas las desventuras posibles, que en la vida nos costaría años conocer y de las cuales las más intensas no nos serían jamás reveladas, porque la lentitud con que se producen nos impediría percibirlas. (p. 96)

En esta medida, todo aquello que está relacionado con la imaginación tiene un papel central en la obra de este escritor. Para Proust lo llamativo de la fantasía es el grado de ambigüedad y sugestión que genera en el individuo. La fantasía permite pasar del sueño a la vigilia, en un tránsito apenas perceptible y que resulta sumamente placentero. La imaginación libera al individuo en la medida en que le permite reconocer sus pasiones y deseos más ocultos. De ahí que este tipo de ambivalencia tenga un papel central al momento de la seducción, tal como puede apreciarse en el obsesivo parecido que Swann encuentra entre la representación de la hija de Jetro y su querida Odette. (p. 240)

La imaginación no sólo se relaciona con la memoria y los recuerdos pasados, sino que también forma parte de la expectación sobre el futuro. Esto se ve, por ejemplo, en una proyección mental mediante 
la que es posible imaginar una puesta de sol o cualquier otro evento semejante. Lo curioso es que aun en este caso se requiere de la experiencia que hemos adquirido previamente y, por ende, de la memoria. Al respecto, el narrador habla del sumo cuidado con que se preparaba para dar un beso a su madre y cómo lo planeaba a detalle:

Así es que me prometía, en el comedor, cuando se iniciara esa comida y yo sintiera acercarse la hora, hacer de aquel beso breve y furtivo todo lo que pudiera hacer con él solo, elegir con la mirada el lugar de la mejilla que iba a besar, preparar mi pensamiento para poder, gracias a ese comienzo mental de beso, consagrar todo el minuto que mamá iba a concederme en sentir su mejilla contra mis labios, como un pintor que sólo obtiene breves sesiones de pose que prepara su paleta haciendo por adelantado, con el recuerdo y las notas, todo aquello para lo que, en verdad, podía prescindir de la presencia del modelo. (p. 36)

En este sentido, se puede establecer cierta superioridad de la imaginación frente a la percepción sensible. Dicha ventaja no sólo se refiere a la diferencia temporal entre una y otra, sino a que las descripciones literarias de un acontecimiento, de un paisaje o de un personaje muestran una diversidad de matices que la realidad no posee por sí sola. ${ }^{6}$ Cuando en una novela las sensaciones se filtran con la interioridad de quien las plasma, adquieren una vitalidad distinta, pues se renuevan y se enriquecen:

No es sólo que la imagen con la que soñamos quede siempre marcada, se embellezca y se beneficie con el reflejo de los colores extraños que por azar la rodean en nuestro ensueño: los paisajes de los libros que yo leía eran para mí paisajes más vivamente representados en mi imaginación que los que Combray ponía ante mis ojos, aunque hubieran sido análogos. (p. 97)

${ }^{6}$ De ahí que muchas veces un individuo se sienta decepcionado, al tener la posibilidad de viajar a un lugar cuya descripción leyó previamente. Otro ejemplo similar se produce cuando leemos un libro y después vemos la adaptación cinematográfica que rechazamos. En este segundo caso lo frustrante radica en el límite que se impone a la imaginación del público. 
EDGAR VITE

Es necesario considerar que la imaginación también puede engañarnos. Una de las características más interesantes y desconcertantes de la mente humana se refiere al hecho de que la conciencia del individuo no es plana, sino que consta de varios niveles. Esta diversidad de niveles es lo que hace posible errar en los juicios sobre la realidad, pues la mente puede confundirse y hacernos creer o percibir cosas que no son. Al respecto, Thomas Reid considera que, debido a esta capacidad, los recuerdos en la infancia y en algunos estados de desorden mental pueden confundirse fácilmente con lo real. ${ }^{7}$

Un rasgo peculiar de la memoria radica en que no devuelve una imagen fría o estática al individuo, sino que de algún modo lo regresa en el tiempo. Rememorar no sólo consiste en preservar intactos ciertos acontecimientos personales, sino que también implica la capacidad de reconstruirlos y en cierto modo revivirlos. Por esta razón, cuando recordamos algo, lo relacionamos con las percepciones sensibles que teníamos en ese momento y esto a su vez implica un mecanismo dinámico. $^{8}$

Las impresiones retenidas por la memoria no se reducen a imágenes visuales, pues además podemos conservar reminiscencias sobre otro tipo de sensaciones, como olores, sonidos, sabores, texturas, etc. Sobre este punto Marcel Proust muestra de modo magistral cómo estas percepciones se preservan en la memoria y se relacionan con la serie de angustias, dolores y miedos propios de un individuo:

Aquella escalera detestada, por la que siempre transitaba tan tristemente, exhalaba un olor a barniz que había en cierto modo absorbido, fijado, esa clase particular de pesar que yo sentía cada noche y lo volvía más cruel para mi sensibilidad porque, bajo esa forma olfativa, mi inteligencia no podía tomar parte [...] Era lo contrario de ese alivio lo que yo

${ }^{7}$ Vid. Thomas Reid, op. cit., p. 203.

${ }^{8}$ Sobre este punto se vuelve necesario distinguir entre recuerdo y percepción. Ambas facultades corresponden a vivencias temporales diferentes; por otro lado, la naturaleza de la percepción es material y en cambio la del recuerdo es inmaterial. Además, la memoria es intencional, pues siempre nos remite al objeto o acontecimiento de donde obtuvimos un recuerdo determinado; en cambio la percepción no se refiere a otra cosa más que a sí misma. Vid. Reid, op. cit., p. 201. 
experimentaba cuando la pena de ir a mi cuarto entraba en mí de manera infinitamente más rápida, casi instantánea, a la vez insidiosa y brusca, por la inhalación -mucho más tóxica que la penetración moral- del dolor particular del barniz de aquella escalera. (p.37)

El escritor francés juega constantemente con la transición que se da entre el sueño y la vigilia, pues considera que en ese proceso se da una apertura especial de la memoria, inclusive con mayor intensidad que cuando se tiene plena conciencia. ${ }^{9}$ El narrador se percata que en esta transición se vincula con otras facultades y procesos gnoseológicos, en los que una pluralidad de sensaciones se entremezcla. De este modo, puede apreciarse una gran diversidad de estados mentales y niveles de conciencia que se relacionan estrechamente con la memoria del individuo:

"Me estoy durmiendo"; y una media hora después, la idea de que ya era tiempo de dormirse me despertaba; trataba de dejar el libro que creía tener aún entre mis manos y soplar la llama, mientras dormía no había cesado de reflexionar sobre lo que acababa de leer, pero estas reflexiones habían tomado un sesgo un poco peculiar; me parecía que yo mismo era lo que la obra decía: una iglesia, un cuarteto, la rivalidad de Francisco I y Carlos V. Esta creencia sobrevivía algunos segundos a mi despertar; no chocaba a mi razón, pero pesaba como una membrana sobre mis ojos y les impedía darse cuenta que la vela ya no estaba encendida. (p. 11)

La unión entre las diversas facultades humanas es tan estrecha que resulta indisociable. El conocimiento humano no sólo se complementa por medio de la sensibilidad y la inteligencia, sino que ambas partes se unifican en una sola vivencia que constituye la experiencia del individuo en su totalidad. Si se analiza con suficiente atención En busca del tiempo perdido, es posible ver cómo Proust describe una serie de experiencias subjetivas alteran nuestra percepción del mundo que nos rodea. ${ }^{10}$

${ }^{9}$ En gran parte de la narración de Marcel Proust, nos encontramos con que la vida se reconstruye como un sueño. De ahí que lo vivido y lo soñado se identifiquen en el recuerdo, pues las diversas percepciones, ideas y rememoraciones se le entregan al escritor como parte de un constante embelesamiento. Vid. Blas Matamoros, op. cit., p. 16.

${ }^{10}$ Esta concepción del alma humana nos remite a la antigua teoría aristotélica, en la que se planteaba la existencia de tres tipos de alma: la vegetativa, la sensitiva y la intelectiva. 
EDGAR VITE

Dicha característica no se reduce a las impresiones de las cosas, sino que también abarca el conocimiento sobre los otros. Al respecto, el escritor francés muestra cómo la opinión que tenemos sobre alguien altera directamente el modo en que ésa persona se presenta ante nosotros. Esto se debe en gran parte a que, cuando pensamos o recordamos a alguien, no sólo nos remitimos a su apariencia física, sino también a la imagen que nos hemos formado de ella:

Pero incluso en las cosas más insignificantes de la vida no somos un todo materialmente constituido, idéntico para todo el mundo, y del que cada uno puede informarse como de un cuaderno de gastos o de un testamento: nuestra personalidad social es una creación del pensamiento de los otros. Incluso la acción sencilla que denominamos "ver a una persona que conocemos" es en parte un acto intelectual. Llenamos la apariencia física del ser que vemos con todas las nociones que tenemos sobre él y, en la apariencia total que imaginamos, esas nociones forman seguramente la mayor parte. (p. 27)

La impresión sobre alguien varía de acuerdo a cada persona, además de que ésta se va alterando con el paso del tiempo, por lo que es posible tener innumerables concepciones sobre un mismo objeto o sujeto 44 a lo largo de la vida. De ahí que la experiencia individual sea tan distinta de la de los demás, aún cuando se comparta el mismo referente. Tal es el caso de la diversidad de recuerdos que el narrador conserva sobre Swann en cada etapa de su vida:

La envoltura corporal de nuestro amigo había sido tan bien atiborrada, al igual que algunos recuerdos relativos a sus padres, que aquel Swann se había convertido en un ser completo y vivo, y tengo la sensación de dejar a una persona para ocuparme de otra muy distinta cuando, en mi memoria, del Swann que conocí más adelante con exactitud, paso al primer Swann -ese primer Swann en quien encuentro los errores encanta-

Para Aristóteles, el hombre posee todas estas capacidades, de modo que sus facultades no se reducen a una dimensión material, sino también posee una parte espiritual. Por lo tanto, el hombre es un caso muy peculiar, pues no sólo goza de las capacidades de los otros seres vivos, sino que sus experiencias se enriquecen con la intelección. Vid. Aristóteles, Acerca del alma, 2000, Madrid, Gredos, trad. Tomás Calvo, pp. 142-5. 
dores de mi juventud, y que, por otra parte, se parece menos al otro que a los personajes que conocí en la misma época, como si nuestra vida fuera un museo en el que todos los retratos de un mismo tipo tienen un aire de familia, una misma tonalidad-, a ese primer Swann lleno de ocio, perfumado por el aroma del gran castaño, de los canastillos de frambuesas y de una brizna de estragón. (p. 28)

En su búsqueda por el tiempo perdido, el narrador se enfrenta con una serie de obstáculos, como es el caso del olvido. El olvido se produce debido a que los nuevos conocimientos desplazan a los anteriores, dependiendo también de los intereses de cada individuo. En este sentido, la memoria puede equiparase metafóricamente con un viejo baúl al que se le van introduciendo recuerdos, pero que tiene una capacidad limitada, por lo que es necesario dar prioridad a unos sobre otros. Este proceso de selección no depende únicamente de la voluntad, pues muchas veces no se retiene lo que se desea y se olvida lo que quiere conservarse:

Hace muchos años de esto. El muro de la escalera por el que vi trepar el reflejo de la bujía hace tiempo que no existe. En mí también hay muchas cosas destruidas que yo creía iban a durar siempre, y se han formado nuevas, dando nacimiento a penas y alegrías que yo no podía prever entonces, del mismo modo que se me hace difícil entender las antiguas. También hace mucho tiempo que mi padre ya no puede decir a mamá "Vete con el niño". La posibilidad de tales horas no renacerá jamás para mí. (p. 46)

Por otro lado, existen ciertos ejercicios nemotécnicos, por medio de los cuales es posible estimular esta facultad y entrenarla para conservar los recuerdos con mayor fijeza y fidelidad. Algunos de los mecanismos más comunes para ejercitar la memoria son la repetición verbal o escrita, la asociación de ideas, la creación de historias o listas que ayudan a retener información más fácilmente. Al respecto, el narrador habla de su vieja afición por clasificar en listas a los actores de una obra de teatro, de acuerdo a sus habilidades histriónicas, con la finalidad de memorizarlos:

Entre la forma en que uno y otro tenían de cortar o de matizar una tirada, las más mínimas diferencias me parecían de una importancia 
EDGAR VITE

incalculable. Y según lo que me decían de ellos, los clasificaba por orden de talentos en listas que me recitaba a mí mismo a lo largo de todo el día, y que habían terminado por petrificarse en mi cerebro y estorbar con su inamovilidad. (p. 84)

Por ello, en esta novela es posible distinguir dos tipos de memoria, una voluntaria y otra involuntaria. La primera corresponde a un proceso gnoseológico y nos brinda un recuerdo más bien objetivo e irrelevante para el sujeto que lo experimenta. En cambio, el segundo tipo de reminiscencia nos trae de golpe una serie de relaciones significativas con nuestro pasado. ${ }^{11}$ Lo curioso es que, en este caso, el proceso para recordar no está sometido a la necesidad, sino que más bien es arbitrario. El narrador cuenta con sumo detalle el modo en que fue capaz de recobrar sus recuerdos de Combray, en la época de su infancia:

Y de pronto apareció el recuerdo. Aquel sabor era el del pedacito de "magdalena" que el domingo por la mañana en Combray (porque ese día yo no salía antes de de la hora de misa), cuando iba a darle los buenos días en su cuarto, me ofrecía mi tía Léonie, después de haberlo empapado en su infusión de té o de tilo. La vista de la "magdalena" no me había recordado nada, hasta que la probé; tal vez porque habiéndola visto después con frecuencia en las mesas de las confiterías, sin comerla, su imagen había abandonado aquellos días de Combray para ligarse a otros más recientes; quizá porque de esos recuerdos dejados tanto tiempo fuera de la memoria nada sobrevivía, todo se había disgregado (p. 56)

En este caso, una sensación funciona como detonador y nos da acceso al pasado, pero no se trata de cualquier tipo de sensación, sino que tiene que ser una muy específica. De manera que, cuando se obtiene una serie de percepciones sobre un mismo objeto, habrá unas que sean más relevantes que otras para identificarlo y conservarlo en la memoria. Por esta razón, es relevante considerar que en este pasaje no

${ }^{11}$ La memoria involuntaria establece una conexión muy estrecha entre la sensación presente y la obtenida previamente. En este sentido podemos percatarnos de que la sensación presente reconstruye el pasado, lo revive, lo reubica en su contexto y establece un puente que conecta ambos momentos. Vid. Gilles Deleuze, op. cit., p. 72. 
es la imagen visual de la magdalena lo que produce el recuerdo, sino su sabor, pues sólo éste tenía la fuerza para producir este tipo de evocación.

Lo característico de este tipo de memoria se debe a que no consiste en un mecanismo gnoseológico voluntario. No se trata de un simple proceso de aprendizaje o retención, que puede perfeccionarse mediante la práctica. Este acceso al pasado es involuntario y por lo tanto responde a la casualidad y no a la intención explícita del sujeto. De modo que no todo individuo puede experimentarlo, por lo que sólo algunos serán capaces de alcanzar los lugares más recónditos de su memoria.

En este mismo sentido, Proust revela que mediante el recuerdo de algo o alguien no se guarda una sola impresión, sino que se retiene una gama muy diversa de aspectos. Esto es propio de situaciones en las que se desea conservar algo con lujo de detalle. Por ejemplo, cuando se rehusa olvidar los rasgos del ser amado, a pesar de la distancia. Al respecto, se narra el recuerdo de Swann sobre los matices que tiene la bella sonrisa de Odette:

A solas él reveía aquella sonrisa, la que Odette había tenido el día antes, diferente de la sonrisa con que lo había recibido tal o cual vez, la sonrisa que había sido una respuesta en el coche, cuando él le había preguntado si la desagradaba al arreglar las catleyas; y la vida de Odette en los otros momentos, de los que él no conocía nada, le parecía, con su fondo neutro de colores, parecida a esas hojas de estudio de Watteau, donde vemos por aquí y por allá, en todos los lugares, en todos los sentidos, dibujadas a lápiz con tres colores sobre papel gamuzado, innumerables sonrisas. (p. 255)

Esto muestra una relación significativa entre el amante y el ser amado, sobre todo en lo que se refiere al deseo de posesión. En este sentido, el recuerdo fragmentario del ser amado resulta insuficiente, pues la serie de imágenes que se conserva sobre dicha persona no la entrega en su totalidad e incluso ésta puede convertirse en una barrera. Lo paradójico consiste en que dicha barrera se interpone precisamente cuando se trata de recuperar el recuerdo del ser amado con mayor intensidad. ${ }^{12}$

${ }^{12}$ Vid. Blas Matamoros, Por el camino de Proust, op. cit., p. 138. 
EDGAR VITE

Por otro lado, mediante esta novela Proust revela el lugar privilegiado que tiene hombre, pues sus experiencias son más ricas que la de cualquier otro ser viviente. En esta medida, la búsqueda en los intrincados rincones de la memoria se caracteriza por su fuerte grado de autoreflexión e introspección. Esto se aprecia en el tono profundamente personal de la narración, aun cuando se habla de otros personajes. Así, se produce el efecto de estar leyendo sobre un individuo y no sobre una trama concreta, por lo que ésta pasa a un segundo plano:

Después de comer, ay, yo estaba obligado a separarme de mamá, que se quedaba a charlar con los otros, en el jardín si hacía buen tiempo, en el saloncito adonde se retiraba todo el mundo si era malo. Todo el mundo, salvo mi abuela, que pensaba que "era una pena estar encerrado en el campo" y que tenía incesantes discusiones con mi padre los días de gran lluvia, porque él me mandaba a leer a mi cuarto en lugar de dejarme afuera. "No es así como van a hacerlo robusto y enérgico -decía ella tristemente-, sobre todo a este niño que tiene tanta necesidad de adquirir fuerzas y voluntad". (p. 19)

Esto se debe en gran parte a que la intención principal de Proust es reconstruir la historia personal de sus protagonistas y en este sentido los recuerdos del narrador sobre su vida pasada no pueden ser comprendidos como meras alusiones o como motivos secundarios, sino que se buscan en sí mismos, en su relación significativa con él. De este modo, se van entretejiendo una serie de relatos que revelan la personalidad de quien los vivió. Sobre este punto es posible remitirse al recuento del narrador sobre cómo adquirió gusto por la literatura y se convirtió en un ferviente lector:

Por debajo de aquellos acontecimientos tan cotidianos, aquellas cosas tan corrientes, yo sentía algo como una entonación, una acentuación extraña. La acción se enredaba y me parecía tanto más oscura porque, en esa época, cuando leía me ponía a pensar durante páginas enteras en cualquier cosa. Y a las lagunas que esta distracción dejaba en el relato, se añadía, cuando era mamá quien leía en voz alta, el hecho de que salteaba todas las escenas de amor. (p. 51) 
Puede apreciarse cómo el protagonista guarda una relación muy particular con el mundo que lo rodea, por lo que las habitaciones, muebles y vestidos son afectados directamente por su contacto con él. El escritor francés muestra en esta novela cómo los objetos personales se impregnan del individuo al que pertenecen con el paso del tiempo. Por esta razón, la subjetividad no se restringe al ámbito interior, sino que tiene una incidencia en el mundo exterior:

Eran esas habitaciones de provincia que - del mismo modo que en ciertas comarcas hay partes enteras del aire o del mar que están iluminadas o perfumadas por infinidad de protozoarios que no vemos- nos hechizan con los miles olores que allí exhalan las virtudes, la prudencia, las costumbres, toda una vida secreta, invisible, superabundante y moral que la atmósfera guarda en suspenso; olores naturales por cierto, y color del tiempo como los del campo cercano, pero ya caseros, humanos y confinados, jalea exquisita, industriosa y límpida de todos los frutos del año que han dejado el vergel por el armario. (p. 59)

Este sentido de pertenencia funciona como una especie de caleidoscopio que transforma la visión del mundo y dota a los objetos con una multiplicidad de brillos, de modo que las cosas adquieren un nuevo significado debido a su vínculo con cada individuo, por lo que adquieren un lugar exclusivo en la historia personal. Sobre este punto es posible hablar de la pieza musical de Vinteuil, que representa el estrecho lazo entre Swann y Odette, por lo que identifican su amor con dicha pieza y, en este sentido, tiene un significado único para ellos. (p. 234)

En busca del tiempo perdido está impregnada de emotividad, por lo que no puede hablarse de un punto de vista objetivo o neutral; se debe a que la voz del narrador se mantiene como una resonancia constante a lo largo de toda la novela. ${ }^{13}$ Esto puede apreciarse cuando

${ }^{13}$ En la manera de Marcel Proust no podemos hablar de la existencia de un objetivismo en el sentido tradicional del término, pues aunque nuestro conocimiento nos remita a algo externo, dicha referencia no es sobre el objeto, sino sobre su vínculo significativo con nosotros. Vid. Gilles Deleuze, op. cit., pp. 37-8. 
EDGAR VITE

el narrador realiza una detallada descripción de un vitral, a través de las diversas sensaciones e impresiones que le produce:

Había uno que era un alto compartimiento dividido en un centenar de pedazos rectangulares, en los que dominaba el azul, como un gran juego de cartas semejante a los que debían distraer al rey Carlos VI; pero ya fuera porque había brillado un rayo, o que mi mirada al moverse hubiera pasado a través de la vidriera, sucesivamente apagada y encendida, un moviente y precioso incendio, al instante siguiente había adquirido el resplandor cambiante de una cola de pavo real, que después temblaba y ondulaba en una lluvia resplandeciente y fantástica que emanaba de lo alto de la cúpula sombría y rocosa. ${ }^{14}$

En el fondo, Proust trata de recobrar el modo en que esta carga de subjetividad se filtra en todo lo que nos rodea, lo que no es una tarea sencilla. En este sentido, es necesario considerar que para este escritor la experiencia no es interna o externa, sino que forma parte de un todo al que se ciñe la vida humana; de ahí que las percepciones sensibles sobre el mundo sean inseparables de la interioridad subjetiva:

Porque, si tenemos la sensación de estar siempre rodeados del alma, no es como si ésta fuera una prisión inmóvil; más bien nos sentimos arrastrados con ella en un perpetuo impulso para sobrepasarla, para alcanzar el exterior, con una especie de descorazonamiento al escuchar siempre alrededor esa sonoridad idéntica que no es eco del exterior, sino resonancia de una vibración interna. (p. 97)

Uno de los aspectos más destacables de la concepción proustiana sobre la memoria consiste en que ésta es presentada como una facultad inmaterial. Esto se debe a que todo recuerdo retenido carece de consistencia física, aún cuando se trate de un objeto material. Lo más llamativo y desconcertante de este proceso cognitivo consiste en que es posible revivir una sensación que hemos dejado de percibir y que de algún modo ha dejado de ser.

${ }^{14}$ Proust, Marcel. En busca del tiempo perdido, 200, Argentina, Losada, trad. Estela Canto, p. 70. 
Por otro lado, hay sensaciones que se vinculan estrechamente con los estados emocionales del individuo, tal como ocurre cuando se entra en contacto con una obra de arte. Un ejemplo de esto se encuentra en la narración de la experiencia estética que se produce al escuchar una pieza musical: "Pudo representarse su extensión, los agrupamientos simétricos, la gráfica, el valor expresivo; tuvo ante sí esa cosa que ya no es música pura que es dibujo, arquitectura, pensamiento, y que permite recordar la música". ${ }^{15}$

Esta característica de la memoria permite experimentar un cierto tipo eternidad, pues gracias a ella las vivencias personales sobreviven al tiempo, se mantienen dentro de cada individuo y es posible construir un puente entre el presente y el pasado. ${ }^{16}$ Por otro lado, lo retenido no se mantiene tal cual, sino más bien tal como se aparece al que recuerda. Así, nos damos cuenta que la búsqueda del escritor francés no es una búsqueda objetiva, sino que se trata de un reencuentro personal. Por esta razón, las remembranzas del narrador sobre Combray no pueden compararse con fieles fotografías, sino que se trata de impresiones subjetivas de dicho lugar:

Como si Combray sólo hubiera consistido en dos pisos reunidos por una escalera angosta y siempre fueran las siete de la tarde. A decir verdad yo hubiera podido responder a quien me interrogara que en Combray había otras cosas, y que Combray existía a otras horas. Lo que habría recordado hubiera sido proporcionado únicamente por el recuerdo voluntario, por la memoria de la inteligencia, y como los datos que la inteligencia da sobre el pasado no conservan nada de ese pasado, nunca tuve ganas de pensar en el resto de Combray. Todo aquello estaba en realidad muerto para mí. (p. 53)

${ }^{15}$ Marcel Proust, op. cit., p. 225.

${ }^{16}$ Además podemos hablar de otro sentido de eternidad, correspondiente a ciertos objetos, como monumentos, edificios, iglesias que poseen una carga histórica que les otorga un lugar especial y por ello perduran en el tiempo. Un ejemplo de esto en la novela de Proust lo encontramos en la iglesia de Combray: "un edificio que ocupaba, si así puede decirse, un espacio de cuatro dimensiones - la cuarta era el Tiempo- desplegando a través de los siglos su nave, que de bóveda en bóveda, de capilla en capilla, parecía vencer y franquear, no sólo unos cuantos metros, sino épocas sucesivas de las que iba a salir victoriosa". Ibid., p. 71. 
EDGAR VITE

Puedo concluir que Proust muestra que la memoria es un reflejo de la inmaterialidad propia de la mente humana, así como el modo en que la subjetividad trasforma nuestra relación significativa con el mundo y con los otros. La reminiscencia implica un modo privilegiado de introspección, en el que el individuo se descubre a sí mismo, a través de su experiencia, y se reconoce en el tiempo. Esto se debe, en última instancia, a que en la búsqueda del tiempo perdido, el recuerdo abre un vórtice para revelar al sujeto su propia identidad. 